\title{
As ordens de indexicalidade de gênero, de raça e de nacionalidade em dois objetos de consumo em tempos de Copa do Mundo 2014
}

\section{Gender, race, and nationality orders of indexicality in two consumed objects during the 2014 World Cup}

Glenda Cristina Valim de Melo*

Universidade Federal do Estado do Rio de Janeiro (Unirio)

Rio de Janeiro, Rio de Janeiro / Brasil

Juliana Tito Rosa Ferreira*

Universidade de Franca (Unifran)

Franca, São Paulo / Brasil

\begin{abstract}
RESUMO: Este artigo pretende apresentar as ordens de indexicalidade de gênero, de raça e de nacionalidade observadas em duas camisetas lançadas em virtude da Copa do Mundo 2014. Para isso, a investigação se embasa nas concepções de linguagem como performance propostas por Austin (1962/1990), Derrida (1972/1988), Bauman e Briggs (1990), Pennycook (2007), nos estudos de gênero sugeridos pelas teorias queer (LOURO, 2008; BUTLER, 1999; FERREIRA, 2016; MELO; MOITA LOPES, 2013; 2014; 2015) e na definição de ordens de indexicalidade indicada por Blommaert (2006). Nesta pesquisa qualitativa interpretativista (MOITA LOPES, 1994), como construto analítico, o estudo se ancorou nas pistas indexicais (WORTHAM, 2001) e na perspectiva de análise de imagens sugeridas por Kress e Leeuwen (1996/2006). Neste estudo, os resultados apontam para sete ordens de indexicalidades, que mobilizam discursos, valores e ideologias sobre o país - especificamente, a respeito de certo tipo de mulher brasileira.

PALAVRAS-CHAVE: ordens de indexicalidade; camisetas; raça; gênero; nacionalidade.
\end{abstract}

\footnotetext{
* glendamelo09@gmail.com

** jujutrf@yahoo.com.br
} 
ABSTRACT: This paper intends to present the indexicality orders of gender, race, and nationality observed on two T-shirts marketed for the 2014 World Cup. This study is therefore based on the concept of language as performance proposed by Austin (1962/1990), Derrida (1972/1988), Bauman and Briggs (1990), and Pennycook (2007), in gender studies proposed by queer theories (LOURO, 2008; BUTLER, 1999; FERREIRA, 2016; MELO; MOITA LOPES, 2013; 2014; 2015) and in the definition of orders of indexicality presented by Blommaert (2006). In this qualitative interpretive research (MOITA LOPES, 1994), the analytical framework is grounded on indexical clues suggested by Wortham (2001), as well as on the perspective of image analysis proposed by Kress and Leeuwen (1996/2006). In this study, the results point to seven different types of orders of indexicality that mobilize discourses, values, and ideologies concerning Brazil, specifically about a certain type of Brazilian woman.

KEYWORDS: orders of indexicality; T-shirts; race; gender; nationality.

\section{Introdução}

A sociedade que entra no século XXI é caracterizada por um tipo de modernidade diferente da que entrou no século XX. Segundo Hall (2003) “as identidades modernas estão sendo 'descentradas', isto é, deslocadas ou fragmentadas” (p. 8). Para o autor, há uma mudança de estrutura que vem transformando a sociedade desde o século XX, uma fragmentação que atinge conceitos até então considerados imutáveis, como o cenário cultural de classe, de gênero, de sexualidade e de raça, que, de acordo com o autor, "no passado, tinham-nos fornecido sólidas localizações como indivíduos sociais". Nesse sentido, Hall (2003) afirma que essas transformações também mudam nossas identidades pessoais e transformam a ideia de sujeito integrado, uno e cartesiano.

Soma-se a isso o fato de vivenciarmos, na perspectiva de Giddens (1991), um momento de transição entre Modernidade e Modernidade Reflexiva, período de dar espaço ao sujeito social fragmentado. Este segundo momento nos proporciona a mudança de olhar do centro para a margem, possibilitando debates sobre temáticas apagadas na Modernidade, como gênero, raça, sexualidade etc. Intrínseca a ela está a possibilidade de reflexividade sobre nós mesmxs. ${ }^{1}$ Para Moita Lopes (2004, p. 162), vivemos

\footnotetext{
${ }^{1} \mathrm{O}$ uso do x visa a contemplar a diversidade de gênero.
} 
tempos em que muitas certezas estão sendo questionadas em um mundo de risco iminente (ecológico e outros), de incertezas (de seres pós-orgânicos, por exemplo) e em um mundo econômico que muitos chamam de novo capitalismo, que necessita de novos conhecimentos para enfrentá-lo. Como os pesquisadores da área da linguagem podem produzir conhecimento sem se envolver com essas questões? Se o fizeram em tempos passados, as mudanças que vivemos, no momento atual, não nos deixam espaço para respirar: é tempo de repensar os percursos epistemológicos que têm nos orientado.

Nesse sentido, de acordo com o autor, estamos vivenciando novas possibilidades de construção de pesquisador(a) e da pesquisa. Esse profissional do contemporâneo questiona e reflete sobre os efeitos do que faz e das questões éticas, partindo do princípio de que não há neutralidade na ciência, da impossibilidade de distanciamento teórico e de hibridismos teórico-metodológico-analíticos. Dessa forma, entendemos que estamos em um momento em que fazer pesquisa implica em fazer política. Além disso, entendemos que para fazê-la, torna-se ímpar o intercâmbio com outras áreas além da linguística, buscando, dessa forma, um caráter interdisciplinar para melhor compreender, segundo Bronckart (1999), "as ações humanas em suas dimensões sociais e discursivas constitutivas” (p. 31).

Dentro desse contexto de reflexividade sobre nós mesmxs, de convergência e de hibridez, trazemos para o centro de nossa pesquisa as mulheres brasileiras, retratadas pela Adidas, patrocinadora oficial da Copa do Mundo no Brasil 2014, em dois objetos de consumo.

Na Copa do Mundo realizada no Brasil, em 2014, a multinacional esportiva Adidas lançou duas camisetas que enfatizavam a construção sexual estereotipada de mulheres brasileiras, gerando polêmicas. Assim, optamos pelos dois objetos para analisar as ordens de indexicalidade de gênero, de raça e de nacionalidade mobilizadas nos dois textos multimodais. ${ }^{2}$ Buscamos, então, responder à seguinte pergunta de pesquisa: que ordens de indexicalidade de gênero, de raça e de nacionalidade são observadas nas camisetas mencionadas?

\footnotetext{
${ }^{2}$ Este artigo faz uso dos dados da dissertação de mestrado de Juliana Tito Rosa Ferreira intitulada "Mulheres brasileiras: a trajetória textual e as entextualizações de dois objetos de consumo em tempos de Copa do Mundo 2014", apresentada à Universidade de Franca em 2016.
} 
Para isso, além dos atos de fala performativos propostos por Austin (1962/1990) e por Derrida (1972/1988), esta investigação também se embasa nos estudos sobre gênero e sexualidade propostos pelas teorias queer (LOURO, 2008; BUTLER, 1999) e no conceito de ordens de indexicalidade propostos por Blommaert (2006; 2010). Para as análises, trabalhamos com as pistas indexicais (WORTHAM, 2001) e as categorias propostas por Kress e Leeuwen (1996/2006) para as imagens.

Salientamos que neste artigo, primeiramente apresentamos o caso das camisetas da Adidas e, em seguida, discutimos as concepções teóricas que ancoram esta pesquisa; depois, abordamos a metodologia de pesquisa e, por fim, mostramos as ordens de indexicalidade de gênero, de raça e de nacionalidade.

\section{$2 \mathrm{O}$ caso das camisetas da Adidas}

De acordo com Bauman (2008), vivemos em uma sociedade de consumo em que até mesmo as pessoas são transformadas em mercadorias. Há um desejo de compra que precisa ser satisfeito, e estamos cercados de objetos, de pessoas e de sentimentos para consumir. Apesar de terem sido retiradas de circulação em razão da repercussão negativa, as camisetas foram criadas para serem compradas, consumidas pelas pessoas - por isso as chamamos de objetos de consumo.

Como sabemos, a Copa do Mundo é um campeonato internacional de futebol que acontece de quatro em quatro anos no qual o país-sede atrai públicos de diferentes lugares - e ao qual os olhares midiáticos voltam-se mais atentamente.

No Brasil, milhões de pessoas comemoraram a escolha do país para sediar o evento de 2014. Contudo, em 2013, o momento era crítico: deparamo-nos com uma série de protestos e manifestações contra a corrupção, contra o custo da Copa, contra a falta de saúde e de segurança, entre outros temas. Essas manifestações e protestos se iniciaram por meio de um grupo de estudantes que fomentavam um movimento contra o aumento da passagem de ônibus em São Paulo, ao qual milhares de pessoas aderiram, indo às ruas clamar por seus direitos, que já não se restringiam apenas às passagens de ônibus, mas à educação, à saúde e a outras esferas da vida política e social. O movimento recebeu o nome de "Vem pra rua". Foi nesse momento, com a ebulição dos protestos, que emergiram assuntos 
diversos, como questões sobre preconceitos, direitos de igualdade e cotas para mulheres no senado, cura gay e racismo.

Nesse contexto, algumas pessoas também se manifestavam contra o próprio evento da Copa do Mundo. As justificativas eram variadas: os custos das construções de estádios, o superfaturamento de obras e a ausência de investimentos em saúde, em educação, em transportes e em outras áreas básicas. Por outro lado, havia manifestantes a favor do evento, que diziam que para a saúde era necessária a formação de mais médicos; para a educação, a qualificação de professores - enfim, argumentos favoráveis e contrários circularam na mídia tradicional, na alternativa e nas redes sociais por alguns dias.

Em muitos eventos de abrangência mundial, como Copas e Olimpíadas, algumas patrocinadoras lançam produtos específicos para o evento. A Adidas, patrocinadora oficial da Copa do Mundo no Brasil de 2014, lançou duas camisetas que geraram polêmicas, ilustradas na Figura 1:

FIGURA 1 - Camisetas para Copa do Mundo 2014 retiradas do Google imagens ${ }^{3}$
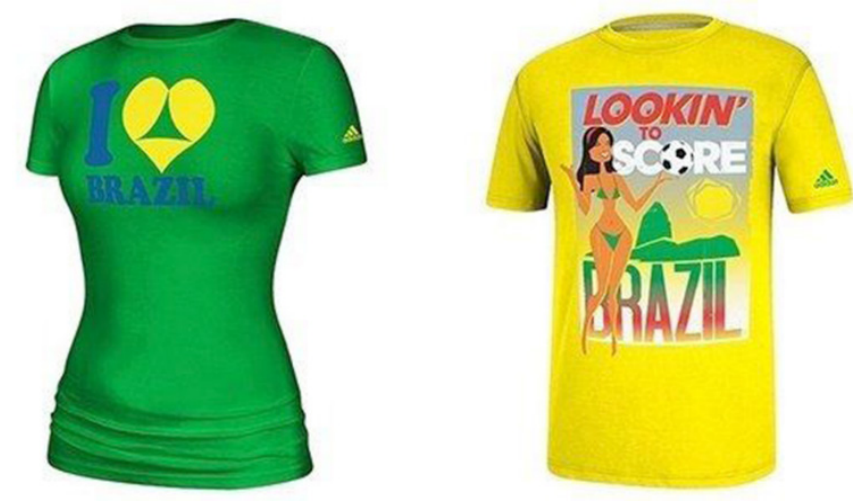

Essas polêmicas se materializaram em uma série de protestos e manifestações na web, em várias línguas e países, tanto na imprensa tradicional quanto em mídias alternativas (blogs, redes sociais, sites feministas, entre outros). Enquanto isso, vários grupos feministas brasileiros e internacionais se posicionaram contra as camisetas, e cidadãos questionaram ou ratificaram

\footnotetext{
${ }^{3}$ As imagens em questão também podem ser encontradas em vários jornais e revistas on-line que circularam notícias sobre o assunto na época. Optamos pelas figuras que circularam no Google imagens tanto pela qualidade quanto pela resolução.
} 
o discurso da mulher brasileira como objeto sexual e de consumo nas mídias sociais; além disso, o próprio Governo Federal brasileiro se manifestou contra o posicionamento machista e misógino observado nos objetos de consumo, visto que eles remetiam aos discursos de algumas mulheres brasileiras como objeto sexual, hipersexualizadas. Considerando que linguagem é ação, nas camisetas em análise, ações estão sendo realizadas, como veremos ao longo do artigo.

\section{Linguagem como performance e ordens de indexicalidade}

Enquanto Noam Chomsky discutia a gramática gerativa nos Estados Unidos, na França, Benveniste tratava a linguagem em uma perspectiva semântica e na Inglaterra, de acordo com Ottoni (2002), Austin propunha o conceito de atos de fala. Segundo Ottoni (2002), para a década de 1960, Austin era considerado um "desconstrutor", alguém que inovou os pensamentos existentes.

Em oposição à filosofia da linguagem tradicional, Austin (1962/1990) se preocupava com a linguagem ordinária. Para o estudioso, não havia fronteiras entre a filosofia e a linguística, pois ambas faziam parte de um mesmo campo. Em suas primeiras conferências, ele nos mostra que a linguagem está para além da descrição, apresentando a proposta dos atos de fala e os compreendendo como atos de fala constatativos - aqueles que descrevem algo, sendo verdadeiros ou falsos - e atos de fala performativos - que indicam uma ação realizada:

O termo "performativo" será usado em uma variedade de formas e construções cognatas, assim como se dá com o termo "imperativo". Evidentemente que este nome é derivado do verbo inglês to perform, verbo correlato do substantivo "ação", e indica que ao se emitir o proferimento está se realizando uma ação, não sendo, consequentemente, considerado um mero equivalente a dizer algo. (AUSTIN, 1962/1990, p. 23)

Austin buscava romper com a tradição de um estudo analítico da filosofia da linguagem. Ele não se preocupava em estruturar, mas sim em refletir sobre a linguagem em uso. Para o autor, no momento de uma enunciação ocorre mais do que uma simples fala: quando alguém profere um ato de fala, uma ação acontece. A derivação do verbo to perform cunha o termo performativo; portanto, os atos de fala performativos são aqueles que realizam uma ação no momento de sua enunciação. Entretanto, o próprio 
Austin percebeu que seriam necessárias algumas condições especiais para que, ao proferir um ato de fala, uma ação acontecesse:

Deve existir um procedimento convencionalmente aceito, que apresente um determinado efeito convencional e que inclua o proferimento de certas palavras, por certas pessoas e em certas circunstâncias: e além disso, que as pessoas e circunstâncias particulares, em cada caso, devem ser adequadas ao procedimento específico invocado. (AUSTIN, 1962/1990, p. 31)

Ao refletir sobre sua própria teoria de atos de fala, Austin (1962/1990) desconsidera toda a dicotomia entre constatativo e performativo. Para o autor, todos os atos de fala tornam-se performativos, ou seja, quando se enuncia, uma ação é realizada. No entanto, de acordo com o estudioso, as estiolações não eram consideradas um ato de fala performativo, noção posteriormente rediscutida por Derrida (1972/1988). Salientamos assim, que para Otoni (2002), Austin discutia, além da linguagem humana, também o humano: "mostrou que a linguagem não se distancia do humano, do corpo, e, de maneira exemplar, mostrou como o corpo e a linguagem se fundem" (p. 138). Nesse sentido, Austin traz a perspectiva social para a linguagem, compreendendo-a como atos de fala que, ao serem proferidos, realizam ações.

Alguns autores releram as teorias da linguagem através dos atos de fala performativos, trazidas por Austin (1962/1990), e contribuíram para a teoria, como Derrida (1972/1988), Bauman e Briggs (1990) e Pennycook (2007). Derrida, (1972/1988), por sua vez, faz algumas críticas ao reler a teoria dos atos de fala performativos, considerando as estiolações como atos de fala performativos. O filósofo acrescenta que todos os signos estão sujeitos à recitação, à reapropriação e à reiteração. Além disso, o autor se posiciona contrário à existência de uma intenção prévia ao discurso. Para ele, nada estaria fora da interação e do discurso.

Nessa releitura dos atos de fala austinianos, Derrida (1972/1988) contribui ao propor que o performativo é naturalizado pela iterabilidade e pela citacionalidade. Em nossas palavras, iterabilidade é a repetição do ato de fala. Por exemplo, nas questões de gênero, repetimos, em contextos distintos, que rosa é para menina, assim como azul é para menino; que boneca é brinquedo de garota, enquanto o carrinho é brinquedo de garoto. Essa repetição naturaliza discursos do que seria "de menina" e "de menino", dando a ideia de substância e de verdade. Por outro lado, a iterabilidade 
pode falhar, surgindo, então, o novo, o transgressivo, a criatividade, a performatividade. Já a citacionalidade refere-se à citação de falas do outro em nossa própria fala: o enunciado é extraído de seu contexto, que foi extraído de outro; em outras palavras, esse ato de fala é passível de incontáveis e incontroláveis citações. Sendo assim, ambos os conceitos estão relacionados ao efeito e à força, uma propriedade repetível que ganha ressignificações de acordo com o contexto.

Além de Derrida, mencionamos aqui as contribuições de Bauman e Briggs (1990) para a compreensão da linguagem como performance. Segundo esses autores, Austin (1962/1990) trouxe-nos a linguagem como fator social, sendo necessário, portanto, olhar para a performance dinâmica não somente pelo viés dos atos de fala performativos mas também em relações estabelecidas com a questão da performatividade, da performance e do performer, implicadas em relações sociais e de poder.

De acordo com os autores, Austin trabalhava com o ato de enunciar, ou seja, com a força desse ato e não com o efeito por ele produzido. Sendo assim, focava-se mais no performativo do que nos sujeitos sociais. Para Austin, o ato de enunciar ganha mais ênfase do que as performances que são construídas e encenadas por meio desses atos.

Já para Bauman e Briggs (1990), a vida social é um processo de performance. Logo, ao falarmos, uma performance é realizada. Para eles, faz-se necessário contextualizar as performances e, antes de pensarmos em dicotomias, devemos pensar em pluralidade, característica do contemporâneo. As diferenças não são mais tidas como binárias, elas são múltiplas. Nessa perspectiva, os autores citados trazem os atos de fala para as questões identitárias. Eles afirmam que para se estudar a performance é necessário que ela esteja inserida em um texto e situada em um contexto.

Abordar a linguagem como ação remete-nos também a Pennycook (2007), pois, para o estudioso, a linguagem "produz as condições que ela descreve” (p. 66), ou seja, a linguagem constrói os sujeitos sociais, os corpos, o mundo. Para ele, "o que une performances não é uma competência que se encontra dentro de cada indivíduo, mas uma grande variedade de forças sociais, culturais e discursivas" (p. 67). É esse emaranhado de variedades que proporciona as construções, as sedimentações de práticas sociais e a reinvenção de nós mesmxs e de outrxs. Já nas palavras de Butler (1999, p. 8), nessa perspectiva de linguagem como performance, "nós fazemos coisas com a linguagem, produzimos efeitos pela linguagem e nós fazemos coisas 
para a linguagem, mas a linguagem é também a coisa que fazemos". Ou seja, a linguagem é ação, efeito, construção, e por meio dela nós e a língua existimos.

Quando agimos por meio da linguagem, fazemos coisas a e com ela, ou seja, encenamos performances como, por exemplo, o ato de batizar, mencionado anteriormente. Nessas ocasiões, estamos também tecendo um laço entre o contexto translocal e local, indexicalizando ou apontando para valores, ideologias e crenças do primeiro no segundo. Esse laço, que precipita do translocal para o local, é conhecido como o fenômeno da indexicalidade (OCHS, 1992; BLOMMAERT, 2006; ROCHA, 2013). Segundo Fabrício (2016, p. 137):

Como uma atividade semântico-textual, a indexicalidade aponta para uma variedade de discursos, narrativas, vozes e convenções sociais - em suma, jogos de linguagem em que nos engajamos e regras que aprendemos a operar pragmaticamente e para explicar metapragmaticamente ao longo de processos que envolvem interação social. Podemos dizer que o jogo indexical em que somos iniciados é parte fundamental nas ideias (metapragmática) de quem somos, de quem os outros são, dos espaços e tempo culturais que habitamos e como os habitamos, que jogos participamos e que convenções nós devemos aprender a seguir. Esta é a razão pelo qual tais jogos têm muita relevância performativa. Os jogos de linguagem modulam, sem determinar e com diferentes níveis de imobilidade e dinamismo, nossas formas de vida e nossas experiências da realidade dentro de quadros espaço-temporais sempre em movimento. (tradução nossa) ${ }^{4}$

Os valores, os discursos, as narrativas, as vozes e as convenções sociais indexicalizadas e hierarquizadas são, então, as ordens de indexicalidade. Em outras palavras, Blommaert (2006) parte das ordens do discurso

\footnotetext{
${ }^{4}$ As semantic-textual activity indexicality points to a variety of discourses, narratives, voices and social conventions - in sum, to language games we engage in and the rules of which we learn to operate pragmatically and to account for metapragmatically along processes involving social interaction. We could say that the indexical games we are initiated into play a fundamental part in the ideas (metapragmatics) of who we are, of who the others are, of what cultural space-times we inhabit and how we inhabit them, which games we take part in, and which conventions we must learn to follow. That is the reason why they have such performative relevance. They modulate without determining, and with different degrees of immobility and dynamism, our forms of life and our experience of reality within ever-moving spatiotemporal frames.
} 
foucaultianas, compreendidas como procedimentos impostos pelas pessoas e/ ou pelos discursos que controlam as produções discursivas, para tratar das ordens de indexicalidade. Tais ordens de indexicalidade, na perspectiva do autor, são estratificadas, valoradas em escalas (termo oriundo da Geografia). Segundo Pinto e Amaral (2016, p. 160):

Esse potencial da articulação tempo e espaço na metáfora de escala é importante pelo fato de que a variação dos significados de uma atividade comunicativa não é um coeficiente do contexto (seja geográfico ou temporal) porque as possibilidades indexicais de um dado texto estão disponíveis sempre ao mesmo tempo, deslizando dos contextos normativos mais vigiados aos contextos imprevistos menos regrados.

Ao lançar as camisetas como homenagem aos brasileiros e às brasileiras para a Copa do Mundo, o texto multimodal "camisetas ou objeto de consumo" aponta para narrativas, vozes e discursos sobre um tipo de mulher brasileira. Esse tipo específico de mulher é construída de forma una, cartesiana e estereotipada. Os efeitos desses discursos que viajam há tempos podem ser observados nas abordagens agressivas e invasivas de estrangeiros às mulheres brasileiras, ${ }^{5}$ como reportados na mídia na época do evento.

\section{As mulheres brasileiras: nacionalidade, gênero e raça pelo viés queer}

Neste estudo, nos embasamos nas teorias queer para compreender as intersecções de gênero com raça e nacionalidade. Para Louro (2001) "queer pode ser traduzido por estranho, talvez ridículo, excêntrico, raro, extraordinário. Mas, a expressão também se constitui uma forma pejorativa com que são designados homens e mulheres homossexuais" (p. 546).

No senso comum, o termo ofende e agride o outro. Segundo Salih (2012) e Louro (2008), as teorias queer se originaram de uma aliança entre três movimentos: teorias feministas, teorias pós-estruturalistas da linguagem e teorias psicanalíticas, que se questionavam sobre o sujeito: “o queer não está preocupado com definição, fixidez ou estabilidade, mas é transitivo, múltiplo e avesso à assimilação” (SALIH, 2012, p. 19).

${ }^{5}$ FALCÃO, C. Violência contra mulheres na copa do Mundo FIFA. Disponível em: <http:/ / averdade.org.br/2014/07/violencia-contra-mulheres-na-copa-mundo-fifa/>. Acesso em 5 abr. 2017. 
Em outras palavras, o termo queer não se restringe apenas aos que assumem uma homonormatividade, mas é muito mais abrangente, criticando xs que colocam à margem todxs aquelxs que são excluídxs por estarem fora do padrão considerado central. Essas teorias são recentes, e de acordo com Louro (2001), "a política queer está estreitamente articulada à produção de um grupo de intelectuais que, ao redor dos anos 90, passa a utilizar esse termo para descrever seu trabalho e sua perspectiva teórica” (p. 546). Outro aspecto relevante para essa vertente teórica é a intersecção de traços performativos ou marcadores como raça, gênero, sexualidade e nacionalidade, entre outros, pois, segundo Barnard (2004) e Sedgwick (1990/2008), essa intersecção permite entender com mais complexidade tais marcadores, que não são fixos e podem mudar de acordo com o momento sócio-histórico (WILCHINS, 2004).

Neste estudo, a intersecção de gênero, raça e nacionalidade torna-se relevante para entendermos a questão da brasilidade. O termo "brasileiro" é um gentílico, adjetivo pátrio, que surgiu com a comercialização do paubrasil. Entretanto, de acordo com Balestrin (2013), é um termo focado e trabalhado no período da ditadura, que ganhou ênfase com a ideia de nação. Nessa busca por uma nação, deparamo-nos com os discursos de que no Brasil não haveria problema raciais, já que brancos, negros e indígenas (con) viveriam de forma pacífica e harmoniosa. Como um dos símbolos dessa nação, temos o futebol, o Pelé, a caipirinha e a mulata. Dessa forma, Corrêa (1996, p. 48) nos diz que:

a mulatice é um gênero consagrado por Di Cavalcanti ou Sargentelli, entre outros, algo assim como um gênero literário, e a mulata é uma figura engendrada, culturalmente construída, num longo processo histórico que a opõe, seja às figuras femininas que são moedas em nossas pesquisas, seja às figuras masculinas que se opõem a elas (opondo-se ao mesmo tempo, ao Branco e ao Negro).

Esses corpos eram retratados pelo pintor Di Cavalcanti e também trazidos pelas ações de Sargentelli, ${ }^{6}$ o qual se autodefinia como "mulatólogo", que por meio de um programa de televisão com grande divulgação na década de 1970, escolhia a melhor e a mais bela dançarina. Sargentelli viajava o mundo com suas mulatas, e reproduzia toda essa construção discursiva e

\footnotetext{
${ }^{6}$ Para maiores informações, acessar a entrevista de Jô Soares com Sargentelli, disponível em: <https://www.youtube.com/watch?v=kem13BVEmOY>. Acesso em: 5 abr. 2017.
} 
performativa de mulher sensual, sedutora, hipersexualizada, com pouca roupa, disponível e como um ponto turístico que deveria ser visitado, cuja tonalidade da pele variava de morena à negra:

a ideia de que a sensualidade se deve a essas raízes negras é reforçada neste período e é fortemente expressa no mito da sexualidade aberta e desinibida dos brasileiros. Esse mito está presente também na divulgação de um tipo de propaganda do país, na publicidade do turismo, que promove, por exemplo, a imagem da mulata: uma mulher sexualmente muito liberada, "quente" e "fogosa", o resultado da miscigenação de um homem branco com uma mulher negra. A publicidade difunde a imagem de um país no qual as pessoas andam quase nuas nas praias, com mulatas, de modo que há uma associação entre as imagens do carnaval com as de paraíso sexual. (HEILBORN, 2006, pp. 49-50)

Durante o período da ditadura militar, a Empresa Brasileira de Turismo (Embratur) foi utilizada pelos militares como meio de vender uma imagem bonita do país. Por meio do turismo sexual, a imagem da mulher brasileira mulata foi propagada com ênfase no corpo, na beleza, para que se pudesse ter uma bela imagem do país, diferentemente da opressão e da violência que aconteciam no período de ditadura no Brasil.

Observamos aqui que a intersecção de gênero, raça e nacionalidade aponta para um tipo de mulher brasileira, mulata e negra e que era exportada em shows ao redor do mundo, como em programas de televisão, por exemplo. Conforme Corrêa (1996), é imprescindível, ao se abordar gênero, tratar também de raça e, no contexto dessa pesquisa, a nacionalidade é outro marcador que se coloca como fundamental. A autora nos conta que durante algum tempo, os médicos discutiam e estudavam xs mulatxs para saber se eram ou não estéreis, tais como as mulas (cruzamento entre égua e jumento), que originaram sua designação. Para a autora, havia uma cultura de que "tanto o negro como a negra precisam branquear para aproximar-se do polo idealizado" (p. 45), que seria o polo branco.

De acordo com Costa (2001), a construção da nação brasileira tem como origem a brasilidade mestiça. Para ele, havia a ideia de misturar as raças para branquear a população, mas, na verdade, ao persistir o mito dos cruzamentos inter-raciais, o que aconteceu não foi um gradativo clareamento da população, mas sim um escurecimento. Em outro vocabulário, observando a raça em uma escala gradativa, teremos a mulher brasileira como uma mulher mestiça, de pele morena escura, conhecida como mulata; além dela, 
há uma série de tonalidades entre negro e branco para denominar a questão de raça/cor no Brasil, sinalizando o quão delicada é o tema.

Quanto mais clara fosse a tonalidade de pele dessa mulher brasileira, mais aceita ela seria. Entretanto, o racismo, o preconceito e a discriminação incidem sobre esses corpos à medida que a pele escurece. Historicamente vemos que os corpos de mulheres escravas negras eram construídos como propriedades (mercadorias) de senhores de engenho, o que dava o direito a esses homens brancos de se apropriar deles de violenta-los (GIACOMINI, 1988). Dessa forma, a escrava era utilizada para desempenhar diversas funções, até mesmo de escrava sexual, já que pela lógica de propriedade, o seu corpo não lhe pertencia. Além de todo esse sofrimento, havia ainda o discurso de que as mulheres negras seduziam os homens. Assim, os discursos de hipersexualização da mulher negra valorizam, no sentido sexual, os seus corpos. Nas palavras de Melo e Moita Lopes (2014, p. 546),

Outro discurso encontrado na sociedade é o da sensualidade e sexualidade das mulheres negras, consideradas "boas de cama", "gostosas", fogosas ou, nas palavras de Piza (1995, p. 58): “[...] o estereótipo da mulher negra sensual, sedutora, irresistível, atração para o pecado (masculino)." Segundo Carneiro (2003, p. 123), há um discurso e mito de que a mulher negra seria "[...] mais erótica ou mais ardente sexualmente do que as demais, crença relacionada às características do seu físico, muitas vezes exuberante."Tais discursos solidificados ainda coconstroem as mulheres negras como objeto sexual.

Esse mesmo mito de hipersexualização pode ser percebido nos estereótipos construídos sobre a mulata. Nesse sentido, considerando a perspectiva dos atos de fala performativos, observamos que esse imaginário sobre essa mulher brasileira de pele morena à escura foi construído, embasando-nos na perspectiva de Derrida, pela iterabilidade e citacionalidade de atos de fala performativos que as legitimam como hipersexualizadas, disponíveis para o sexo, fogosas, cujo corpo racializado de morena à negra pode ser tocado sem permissão. Além disso, há a construção discursiva e performativa de que essa mulher, especificamente, sabe sambar e realiza performances extraordinárias na cama. Por outro lado, os mesmos valores, vozes, discursos e/ou narrativas não são indexicalizados em relação à mulher brasileira branca.

Percebemos, então, que a interseccionalidade entre gênero, raça e nacionalidade apontam para discursos diferentes sobre as mulheres 
brasileiras e sinalizam que esses marcadores não são de fixidez, e sim construções históricas, sociais, discursivas e performativas. Além disso, quando interseccionados, apontam para sentidos que não teriam se não estivessem imbricados.

Quando observamos os dois objetos de consumo aqui em análise, repetem-se as construções discursivas e performativas de uma única mulher brasileira marcada pela pele parda, a cor da miscigenação, que encena performances identitárias de uma mulher fácil, acessível, disponível para o sexo, objeto sexual, submissa. Partindo do princípio trazido por Wilchins (2004) e por Salih (2012), as mulheres brasileiras retratadas nas camisetas da Adidas seriam resultados ou efeitos dos discursos sobre gênero, raça e nacionalidade disseminados e iteráveis ao longo de décadas.

\section{As ordens de indexicalidade de gênero, raça e nacionalidade}

Esta pesquisa é caracterizada como qualitativa interpretativa (MOITA LOPES, 1994), ou seja, possibilita o acesso indireto ao fato de pesquisa “através da interpretação dos vários significados que o constituem” (p. 331). Nesse tipo de investigação o particular contribui para uma generalização que se constrói intersubjetivamente. Vale mencionar que para analisá-las no corpus, utilizamos uma das pistas indexicais propostas por Wortham (2001). Apesar dessas pistas serem usadas para estudar posicionamento interacional, podem sinalizar também as ordens de indexicalidade mobilizadas nas camisetas. Assim, a pista indexical de referência é entendida aqui, nas palavras de Melo e Moita Lopes (2015), como "os elementos do mundo ao qual o narrador se refere" (p. 62).

Em relação às análises das imagens, seguimos a proposta de Kress e Leuman (1996/2006). De acordo com os autores, durante o século XX, a linguagem não verbal começou a interagir com outros recursos semióticos, de maneira que é comum encontrarmos diferentes textos multimodais. A escolha desses diversos recursos que compõem os textos mencionados acontece tal qual a escolha de índices linguísticos. Sendo assim, a escolha de imagens e/ou palavras é carregada de significações.

Os autores ainda sugerem que, como a linguagem verbal, as imagens proporcionam a representação do mundo social, das identidades, servindo também como mensagem. Não há uma estratégia única e singular capaz de analisar cada elemento que proporcionará o discurso que dali emerge, mas sim um conjunto de estratégias e elementos, ou seja, um todo que é capaz 
de distinguir os discursos que ali borbulham. Para isso, faz-se necessário observar esse todo. Os autores propõem separar as imagens em alguns planos. Nesse sentido, o que está saltando da imagem pode ser considerado como primeiro plano, e o que vem em um nível atrás, o segundo plano, são as imagens com mais de dois planos. Em outras palavras, observamos as dimensões que estão presentes na imagem. Outro fator relevante são as cores e as combinações dessas dimensões presentes nas imagens, que sinalizam mais um traço a ser analisado e também as ordens de indexicalidade em investigação.

Seguindo para a análise, primeiramente, apresentamos uma breve análise da camiseta verde e concomitantemente as ordens de indexicalidade mobilizadas no objeto de consumo; a seguir, apresentamos a camiseta amarela e suas respectivas ordens de indexicalidade.

FIGURA 2 - Camiseta verde Adidas

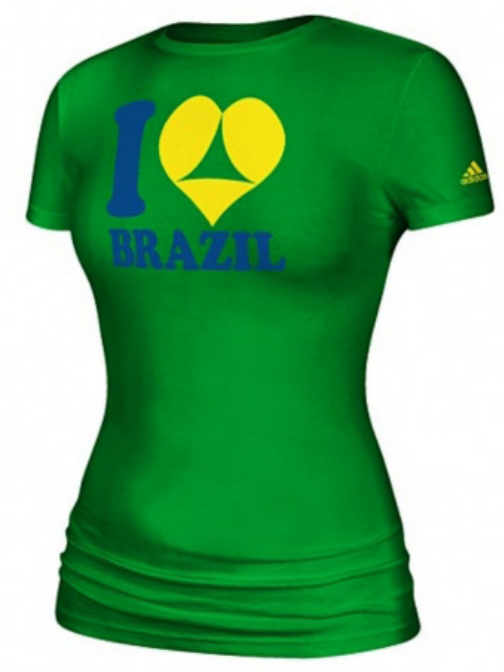

O objeto de consumo em questão (Figura 2) é predominantemente verde, formado por curvas, seios, cintura fina, mangas curtas que indicam ser uma camiseta direcionada para o público feminino, especificamente no modelo conhecido por baby look, que é justo. Além do verde, o produto é composto pelas cores azul anil e amarelo, sinalizando as cores da bandeira brasileira e indexicalizando o país. A referência $I(e u)$ em azul anil está em primeiro plano, bem como a figura que é ambígua, representando ao mesmo 
tempo um coração e/ou uma bunda ${ }^{7}$ com biquíni fio dental, indicando, assim, um equilíbrio entre o índice linguístico e a imagem - ou seja, que ambos têm a mesma importância no texto. $\mathrm{O}$ mesmo não ocorre com a referência Brazil, que está em segundo plano mostrando o foco principal no texto multimodal.

De acordo com Bechara (2009), a figura de linguagem ambiguidade é um recurso que proporciona mais de um sentido, ou seja, sentidos diversos em uma mesma mensagem. Dessa forma, a figura ambígua pode ser lida de duas maneiras, como a imagem de um coração amarelo que indexa o verbo to love, que significa amar, emergindo o sentido de "eu amo Brasil", ou o coração amarelo sinaliza uma bunda invertida, bem definida, vestida por um biquíni fio dental verde, mostrando uma mulher de costas cuja cintura é bem fina, implicando em outro sentido, o de "eu amo a bunda brasileira".

Assim, as pistas indexicais mencionadas mobilizam uma primeira ordem de indexicalidade no primeiro objeto de consumo em análise, que elege uma parte específica do corpo das mulheres brasileiras como aquela que mais merece destaque, apontando para discursos em que essas mulheres são construídas como aquelas que possuem as bundas mais belas, as maiores, como preferência nacional e também de estrangeirxs, já que foi lançada para um evento esportivo internacional e pela escolha da língua inglesa.

Nesta investigação também precipita a ordem de indexicalidade "consumo das camisetas por mulheres". Com base nas curvas dos seios do manequim e da imagem ambígua, pode ser o consumo dos objetos por mulheres que desejariam outras mulheres, sinalizando que os corpos femininos brasileiros poderiam ser desejáveis também por mulheres. Outra possibilidade seria vender o produto para uma mulher que segue determinado padrão corporal de beleza. Por último, com base nas pistas indexicais I e Brazil, encontramos a ordem de indexicalidade que aponta para o público do objeto de consumo, ou seja, apesar das camisetas serem uma homenagem a brasileirxs, seu consumo poderia ser direcionado às / aos estrangeirxs de vários países e que compreendessem tais pistas. Além disso, também poderiam ser brasileirxs que consomem linhas de produtos estrangeiros.

\footnotetext{
${ }^{7}$ A opção pelo índice linguístico ocorreu, porque glúteos ou nádegas femininas não atenderiam aos sentidos dos textos modais e nem aos discursos sobre o corpo de um tipo de mulher brasileira.
} 
Quanto à segunda camiseta (Figura 3) as linhas retas, as mangas mais compridas e o ato de fala lookin' to score ("fazer gols") mostram que a camiseta pode ser um produto para um público masculino, justificado pelo manequim em que se encontra:

FIGURA 3 - Camiseta amarela Adidas

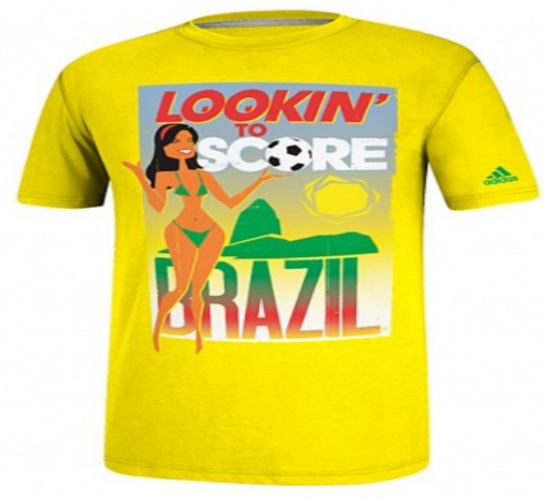

Em relação às cores, o amarelo nos remete ao Brasil; além disso, essa cor sinaliza descontração, alegria, sol e verão. O país também é indicado tanto pelo verde das matas como pelo azul claro do céu. Já o vermelho pode se referir ao desejo, à paixão - cor que aparece tanto no início quanto no fim da imagem e se mescla ao laranja, enfatizando o calor, o verão, a diversão e a liberdade. As cores apontam para um país tropical, alegre, quente, ensolarado, despojado, divertido, em que se usa pouca roupa, e com mulheres pardas, cujos corpos são magros e bonitos.

No objeto de consumo em análise, em primeiro plano, há uma mulher morena, de cabelos pretos, longos e lisos, com uma faixa ou uma tiara cor de rosa que reforça sua feminilidade. O corpo moreno contrasta com o fio dental verde que simboliza o Brasil, é curvilíneo e de cintura bem fina, mostrando um padrão de beleza para essa mulher, brasileira e de origem carioca, indicado pelo Pão de Açúcar em verde, em segundo plano.

Essa mulher, cuja tonalidade de pele pode ser compreendida como morena/morena jambo, tem um corpo sensual, está de braços abertos, e a mão esquerda segura uma bola, também em primeiro plano, indicando uma recepção aos turistas da Copa do Mundo. A bola de futebol é preta e branca, não necessariamente a bola oficial do evento, mas ela não quebra o equilíbrio das cores, e marca o evento. 
Aqui temos mobilizadas as ordens de indexicalidade que recuperam discursos que colocam o Brasil como o país do futebol, indicado pela bola, com grandes jogadores e cujo esporte é popular; vemos também outra ordem de indexicalidade que aponta para um tipo de mulher brasileira, aquela parda, hierarquizada como um dos pontos turísticos conhecidos no país, o Pão de Açúcar, que deve ser visitado ou conhecido. Em outras palavras, uma mulher brasileira, cuja pele não é branca, é sensual, objetificada e igualada a um ponto turístico.

O verbo no infinitivo to score, na cor branca, apresenta vários sentidos, tais como marcar, pontuar, sublinhar e escrever partitura ${ }^{8}$; porém, ao estar associado a uma bola de futebol, a qual se refere à letra "o", indexa os sentidos de marcar, pontuar, cobrar pênaltis e fazer gols. Já o verbo lookin' to, que está no gerúndio e de forma abreviada, escrito em vermelho, cor da paixão e do desejo, mostra uma linguagem cotidiana e coloquial. Esse verbo indexa sentidos como focar e esperar (no sentido de expectativas), e é uma expressão que reforça o evento Copa do Mundo no Brasil. Ressaltamos também que as duas letras "o", de looking, compõem dois olhos e estão direcionados para o lado direito do texto, ou para a bola. Acrescenta-se a isso o fato de que Lookin' to score traz uma expectativa em fazer gols e conquistar um campeonato, mas também é uma gíria, uma expressão sexual. De acordo com Cambridge Dictionary, significa ter sucesso em seduzir alguém sexualmente; ${ }^{9}$ já para o Urban Slang Dictionary, um dicionário de gírias, é fazer sexo com alguém que você geralmente acabou de conhecer. ${ }^{10}$ Aqui, o objeto de consumo também é produzido em língua inglesa sinalizando o público como na análise da Figura 2.

Todas essas pistas indexicais precipitam aqui uma ordem de indexicalidade que apresenta um tipo de mulher brasileira, a morena, de corpo sensual, de formas físicas como hipersexualizadas e disponível para o sexo, retomando os discursos que constroem de forma uniforme as mulheres brasileiras, especificamente, um tipo delas, como aquelas que devem ser conhecidas/visitadas, experimentadas e estão disponíveis para esse tipo de abordagem.

\footnotetext{
${ }^{8}$ Mais informações disponíveis no site: <http://pt.bab.la/dicionario/ingles-portugues/ score $>$. Acesso em: 12 jul. 2016.

9 "To succeed in seducing someone sexually."

10 "To have sex with someone that you have usually just met."
} 
O Pão de Açúcar, em verde, posicionado no mesmo plano da referência "Brazil" e "sol", sinaliza, de forma fálica, um famoso símbolo do turismo carioca. A referência ao país aparece em verde, vermelho e laranja, indicando um lugar do verão, da descontração, da liberdade, da paixão e do desejo. Nesse sentido, observamos a ordem de indexicalidade de hipersexualização do país, sugerida pelo ponto turístico citado, que colocaria o Rio de Janeiro como uma cidade mais hipersexualizada que outras, visto que os pontos turísticos presentes nas camisetas estão nessa cidade. Além disso, observamos outra ordem de indexicalidade que destaca o país como um ponto turístico sexual, assim como outros países, retomando discursos que circularam desde a ditadura sobre esse tipo de turismo.

Como podemos observar nos objetos de consumo aqui analisados, é possível perceber que sete ordens de indexicalidade mobilizam, em nível local, discursos e valores que circulam sobre o país e, especificamente, sobre as mulheres brasileiras. Na primeira, a bunda é a parte do corpo das mulheres brasileiras mais desejada tanto por brasileiros quanto por estrangeiros; a segunda ordem indica o desejo sexual entre mulheres; a terceira aponta para o público do objeto de consumo, ou seja, estrangeirxs de vários países e que compreendam essas pistas em língua inglesa; a quarta aponta para o Brasil como o país do futebol; a quinta hierarquiza e objetifica as mulheres brasileiras como um ponto turístico; a sexta indica que essas mulheres são disponíveis para sexo, hipersexualidazadas e abertas às investidas sexuais; e, por fim, a sétima elenca o país como um lugar para turismo sexual.

Essas ordens apontam para discursos, ideologias e valores que entrelaçam gênero, raça e nacionalidade na medida em que coloca no centro um tipo de mulher brasileira, construída como tal pela iterabilidade. Com base em Derrida (1972/1988), podemos afirmar que os atos de fala performativos marcam esses corpos como hipersexualizados, disponíveis para sexo, abertos às abordagens de um ponto turístico de mulheres brasileiras de certa tonalidade ou raça. Assim, a mulatice (CORRÊA, 1996), consagrada por Di Cavalcanti e Sargentelli, é retomada no corpo da morena de um dos objetos de consumo.

\section{Considerações finais}

A linguagem, na perspectiva performativa (AUSTIN, 1962/1990), proporciona o entendimento de como acontece a construção de diversas práticas sociais. É por meio dos atos de fala performativos, repetidos 
pela iterabilidade e pela citacionalidade (DERRIDA, 1972/1988), que se constroem as normas, as regras, o poder central, o certo e o errado. Constroem-se verdades, corpos para serem consumidos, desejos de pertencer a grupos com elevada classe social, necessidade de embranquecimento da pele, de alisamento dos cabelos e possuir todas as tecnologias possíveis, propagadas pelas diversas mídias, para todxs se aproximarem do padrão.

Percebemos que nas camisetas, pelas ordens de indexicalidades, são precipitados discursos, crenças e ideologias sobre um tipo de mulher brasileira que viajam desde o período da ditadura até atualmente. Esses discursos naturalizam e corroboram a hipersexualização/objetificação de um tipo de mulher brasileira. Constituem, portanto, atos de fala performativos que constroem uma mulher brasileira vista como prostituta, um atrativo turístico, alguém com uma única característica, a sexual.

Ao recorrermos às teorias queer, percebemos que a intersecção entre gênero (mulher) e nacionalidade (brasileira) aponta para a sexualidade. Além disso, se interseccionarmos à raça, teremos a construção de uma mulher brasileira mulata, presente nos objetos de consumo, em análise nesta pesquisa. Utilizamos as teorias queer justamente para questionar essa normalização, que causa sofrimento para muitos corpos - neste caso, principalmente às mulheres brasileiras de pele escura à negra.

\section{Referências}

AUSTIN, J. L. (1962). Quando dizeré faz̧er: palavras e ação. Tradução e apresentação de Danilo Marcondes de Souza Filho. Porto Alegre: Artes Médicas, 1990.

BALESTRIN, P. A. "Nem toda brasileira é bunda": gênero e brasilidade no cinema nacional. Textura, Canoas, v. 13, n. 24, p. 90-104, 2013.

BARNARD, I. Queer race: cultural interventions in the racial politics of queer theory. New York: Peter Lang, 2004.

BAUMAN, R.; BRIGGS, C. L. Poetics and performance as critical perspectives on language and social life. Anual Review of Anthropology, Palo Alto, v. 19, p. 59-88, 1990.

BAUMAN, Z. Vida para consumo: a transformação das pessoas em mercadoria. Tradução de Carlos Alberto Medeiros. Rio de Janeiro: Zahar, 2008.

BECHARA, E. Moderna Gramática Portuguesa. Rio de Janeiro: Nova Fronteira, 2009. BLOMMAERT, J. Social linguistics scales. London: Working Papers Urban Language \& Literacies, 2006. 
BLOMMAERT, J. The sociolinguistics of Globalization. Cambridge: Cambridge University Press, 2010.

BRONCKART, J. P. (1999). Atividade de linguagem, textos e discursos: por um interacionismo sociodiscursivo. Tradução de Anna Raquel Machado e Péricles Cunha. 2. ed. São Paulo: Educ, 2007.

BUTLER, J. Problemas de gênero: feminismo e subversão da identidade. Tradução de Renato Aguiar. Rio de Janeiro: Civilização Brasileira, 1999.

CORRÊA, M. Sobre a invenção da mulata. Cadernos Pagu, Campinas, n. 6/7, p. 35-50, 1996.

COSTA, S. A mestiçagem e seus contrários: etnicidade e nacionalidade no Brasil contemporâneo. Tempo Social, São Paulo, v. 13, p. 143-158, 2001.

DERRIDA, J. (1972). Signature event context. In: . Limited Inc. Evanston: Northwestern University Press, 1988. p. 1-23.

FABRÍCIO, B. F. Mobility and discourse circulation in the contemporary world: the turn of the referential screw. Revista da Anpoll, Florianópolis, n. 40, p. 129-140, jan./jun., 2016.

FERREIRA, J. T. R. A trajetória textual e as entextualizaçôes de duas camisetas esportivas em tempos de Copa do Mundo 2014. 2016. 120f. Dissertação (Mestrado em Linguística) - Universidade de Franca, Franca, 2016.

GIACOMINI, S. M. (1988). Mulher e escrava: uma introdução histórica ao estudo da mulher negra no Brasil. 2. ed. Curitiba: Appris, 2013.

GIDDENS, A. As consequências da modernidade. Tradução de Raul Fiker. São Paulo: Unesp, 1991.

HALL, S. A identidade cultural na pós-modernidade. Tradução de Tomas Tadeu da Silva e Guacira Lopes Louro. 7. ed. Rio de Janeiro: DP\&A, 2003.

HEILBORN, M. L. Entre as tramas da sexualidade brasileira. Estudos Feministas, Florianópolis, v. 14, n. 1, p. 43-59, 2006.

KRESS, G.; LEEUWEN, T. (1996). Reading images: the grammar of visual design. New York: Routledge, 2006.

LOURO, G. L. Teoria queer: uma política pós-identitária para a educação. Estudos Feministas, Florianópolis, v. 9, n. 2, p. 546-533, 2001.

LOURO, G. L. Gênero e sexualidade: pedagogias contemporâneas. Pro-Posições, Campinas, v. 2, n. 56, p. 17-23, 2008.

MELO, G. C. V.; MOITA LOPES, L. P. As performances discursivo-identitárias de mulheres negras em uma comunidade para negros na Orkut. Delta, São Paulo, v. 29, p. 237-265, 2013. 
MELO, G. C. V.; MOITA LOPES, L. P. A performance narrativa de uma blogueira: "tornando-se preta em um segundo nascimento". Alfa Revista Linguística, Araraquara, v. 58, p. 541-56, 2014.

MELO, G. C. V.; MOITA LOPES, L. P. You're a beautiful light brown-skinned woman: the textual trajectory of a compliment that hurts. Trabalhos em Linguistica Aplicada, Campinas, v. 54. p. 53-78, 2015.

MOITA LOPES, L. P. Pesquisa interpretativa em linguística aplicada: a linguagem como condição e solução. Delta, São Paulo, v. 10, n. 2, p. 329-338, 1994.

MOITA LOPES, L. P. Contemporaneidade e construção de conhecimento na área de estudos linguísticos. SCRIPTA, Belo Horizonte, v. 7, n. 14, p. 159-171, 2004.

OCHS, E. Indexing gender in rethinking context: language as an interactive phenomenon. In: DURANTI, A.; GOODWIN, C. (Ed.). Cambridge, UK: Cambridge University Press, 1992. p. 335-358.

OTTONI, P. John Langshaw Austin and the performative view of language. Delta, São Paulo, v. 18, n. 1, p. 117-143, 2002.

PENNYCOOK, A. Performance and performativity. In: Global Englishes and transcultural flows. New York: Routledge, 2007.

ROCHA, L. L. Teoria queer e a sala de aula de inglês na escola pública: performatividade, indexicalidade e estilização. 2013. 255f. Tese (Doutorado em Linguística Aplicada) - Faculdade de Letras, Universidade Federal do Rio de Janeiro, Rio de Janeiro, 2013. PINTO, J. P; AMARAL, D. Corpos em trânsito e trajetórias textuais. Revista da Anpoll, Florianópolis, n. 40, p. 151-164, jan.-jun., 2016.

SALIH, S. Judith Butler e a teoria queer. Tradução de Guacira Lopes Louro. Belo Horizonte: Autêntica, 2012.

SEDGWICK, E. K. (1990). Epistemology of the closet. London: Penguin, 2008.

WILCHINS, R. Queer theory, gender theory: an instant primer. Los Angeles: Alyson Books, 2004.

WORTHAM, S. Narratives in action: a strategy for research and analysis. New York: Teacher College Press, 2001.

Data de submissão: 19/7/2016. Data de aprovação: 3/3/2017. 